\title{
Preparation and Characterization of Polyurethane Nanocapsules Containing Cassia alata Linn. Extract
}

\author{
Prateepthong D. and Komboonchoo S.
}

\begin{abstract}
Polyurethane nanocapsules containing Cassia alata leaves extract were synthesized by an emulsion diffusion process. The influences of stirring speed and dilution time were studied on the chemical and physical properties of nanocapsules. Fourier Transform Infrared Spectroscopy (FTIR) was used to study the chemical structure of nanocapsules and Cassia alata leaves extract. Size distribution and morphology of nanocapsules were examined using laser particle size analyzer and Scanning Electron Microscopy (SEM) respectively. The encapsulated were applied to finish cotton fabrics to enhance antibacterial property. The results revealed that polyurethane nanocapsules containing Cassia alata leaves extract were successfully synthesized by an emulsion diffusion method. The dilution time influenced encapsulation yield. The stirring speed and dilution time do not have a significant effect on particle size distribution. The obtained nanocapsules are rather spherical shape and smooth surface. Cotton fabrics finished with nanocapsules showed antibacterial activity against Staphylococcus aureus.
\end{abstract}

Index Terms-Nanocapsules, polyurethane, Cassia alata, emulsion diffusion method.

\section{INTRODUCTION}

For the last decade, interests in encapsulation have been increased. This technique widely used in pharmaceutical, chemical, cosmetics, food processing and in recent years for textile finishing [1]. Two common encapsulations are microencapsulation and nanoencapsulation. Those techniques provide long lasting effects for the release of active agents [2]. Moreover, encapsulation creates physical and chemical stabilization improve shelf life and protection of active agents from the surroundings [3].

Nanoencapsulation technique is a process by which small particles are coated within wall materials which can be homogeneous or heterogeneous matrix to form capsules at a nanoscale range [4]. The finishing of textiles using nanoencapsulation is claimed to be more durable. The nano-size particles have higher surface area than conventional ones which lead to higher efficiency [5].

Cassia alata is an ornamental shrub. It has been reported to contain anthraquinones. Several parts of Cassia alata have widely been used in medicine. They exhibit several therapeutic properties, such as antibacterial, antifungal and analgesic. Cassia alata leaves contain chrysophanic acid as active ingredient. It is employed for the treatment of

Manuscript received August 9, 2014; revised October 12, 2014.

Donnapha Prateepthong and Sunsanee Komboonchoo are with the Department of Industrial Chemistry, Faculty of Science, Chiang Mai University, Chiang Mai, Thailand, 50200 (e-mail: namdonnapar@hotmail.com, sunsanee.k@cmu.ac.th) ringworm and other fungal infections of the skin. The antibacterial activity of crude extract was predominantly against Gram-positive organisms [6]-[9]. Therefore, in the present work, extracts of Cassia alata leave were applied as the core of nanocapsules to enhance antibacterial function. Polyurethane nanocapsules were prepared using emulsion-diffusion process. The effects of stirring speed and dilution time on some chemical and physical properties were investigated by Fourier transform infrared spectroscopy (FTIR), particle size analyzer and scanning electron microscope (SEM).

\section{METHODOLOGY}

\section{A. Materials}

Cassia alata leaves extract was used for obtaining the antimicrobial extract. The plants were collected from Phichit province, Thailand. 95\% ethanol (Carlo Erba, France) was used as solvent for plant extraction. Diphenyl methylene diisocyanate (MDI) (Acros organics, USA) and 1,4-butanediol (BDO) (Acros organics, USA) were used as shell forming monomers. Ethyl acetate (EtAc) (Carlo Erba, France) and acetone were used as solvents. Tween 20 (Polyethylene glycol sorbitan monolaurate) was applied as emulsifier. Sodium dodecyl sulfate (SDS) (Carlo Erba France) was used as a surfactant.

\section{B. Preparation of Cassia alata Leaves Extract}

Leaves of Cassia alata Linn or Candelabra Bush were dried in a temperature range of $40-50{ }^{\circ} \mathrm{C}$. Dry leaves were torn into small pieces and ground using miller. The powder obtained after grinding was used for extraction. Cassia alata Linn powder was extracted by soxhlet apparatus. $95 \%$ ethanol was applied as an extraction solvent. The extraction was carried out at $80^{\circ} \mathrm{C}$ for $24 \mathrm{~h}$, and then the extract was filtrated. The filtrate was dried using a rotary evaporator under reduced pressure at a temperature of $40^{\circ} \mathrm{C}$.

\section{Preparation of Nanocapsules}

Nanocapsules were prepared using an emulsion diffusion method [10]. This method can be categorized into four steps, i.e. mutual saturation, emulsification, diffusion and purification. Mutual saturation step was processed to reach thermodynamic equilibrium. Distilled water which is the continuous phase and ethyl acetate, EtAc which is the dispersed phase $(2: 1 \mathrm{v} / \mathrm{v})$ were mutually saturated for $24 \mathrm{~h}$. For the emulsification step, $0.75 \mathrm{ml}$ of crude extract of Cassia alata and $5.18 \mathrm{~g}$ of MDI were dissolved in $30 \mathrm{ml}$ of a binary mixture of acetone/ethyl acetate saturated with water, and then this phase was emulsified with $60 \mathrm{ml}$ of the aqueous 
phase containing Tween 20 with the use of a high speed homogenizer (HG-15A, Daihan, Korea) at an experimental stirring speed during $50 \mathrm{~min}$. The effect of stirring speed (4050 6500 and $8100 \mathrm{rpm}$ ) was investigated. This process continues until the expected droplet size of the emulsion was reached. After that, $10 \mathrm{ml}$ of aqueous solution containing 2.1 $\mathrm{g}$ of BDO was added to conduct the polymerization reaction. Diffusion step was made to induce the formation of polymeric shell, the solution was transferred into a double walled vessel, nanocapsules were maintained in suspension under a stirring speed of $500 \mathrm{rpm}$ for different dilution times, which were 2, 4 and $6 \mathrm{~h}$. The diffusion of EtAc from the inner phase to the outer phase for the nanosuspension was made by subsequently added distilled water to the emulsion. The volume of distilled water was approximately twice the volume of the emulsion. The nanocapsules from emulsion were filtrated and washed twice with water to remove unreacted substances, and then dried at $50{ }^{\circ} \mathrm{C}$ for $24 \mathrm{~h}$.

TABLE I: EXPERIMENTAL PARAMETERS FOR NANOCAPSULES PREPARATION

\begin{tabular}{ccc}
\hline \hline Sample & $\begin{array}{c}\text { Speed } \\
(\mathrm{rpm})\end{array}$ & $\begin{array}{c}\text { Dilution time } \\
(\mathrm{h})\end{array}$ \\
\hline 1 & 4050 & 2 \\
2 & 6500 & 2 \\
3 & 8100 & 2 \\
4 & 4050 & 4 \\
5 & 6500 & 4 \\
6 & 8100 & 4 \\
7 & 4050 & 6 \\
8 & 6500 & 6 \\
9 & 8100 & 6 \\
\hline \hline
\end{tabular}

\section{Chemical Analysis}

Fourier transform infrared spectroscopy (FTIR) was applied to investigate the chemical structure of crude extract, polyurethane and resultant nanocapsules. The experiments were performed on Fourier transform spectrometer (Perkin elmer, Spectrum GX). The samples were ground and mixed with $\mathrm{KBr}$ to make pellets. FTIR spectra were obtained in the transmission mode and collected from 400 to $4000 \mathrm{~cm}^{-1}$.

\section{E. Encapsulation Yield}

The encapsulation yield was calculated as the ratio of the recovered mass of nanocapsules and the mass of monomers and extract of Cassia alata introduced. It can be expressed as follows:

$$
\eta(\%)=\frac{m_{\text {nanoparticles }}}{\sum m_{\text {monomer Cassia Alata Linn. }}} \times 100
$$

\section{F. Particle Size and Size Distribution}

Nanocapsules were analyzed for their mean diameter and size distribution using a Mastersizers Serie DTS (Marvern Instrument). All measurements were done in triplicate, the nanocapsule suspensions were dispersed in ethanol at room temperature before measurement.

\section{G. Morphology of the Nanocapsules}

Scanning Electron Microscopy (SEM) was used to study the shape and surface of encapsulated polyurethane nanocapsules using Scanning electron microscope (JEOL/EO JSM 5910LV). Nanocapsules were coated with gold by sputtering and performed with suitable magnification.

\section{H. Antibacterial Activity}

Cassia alata extract and cotton fabrics finished with resultant nanocapsules were tested antibacterial function against Staphylococcus aureus using a Disc assay (Screening method).

\section{RESULTS AND DISCUSSION}

\section{A. Formation and Chemical Structure of Nanocapsules Containing Cassia alata Leaves Extract}

The emulsion-diffusion method was used to prepare nanocapsules loaded Cassia alata leave extract. Nanocapsules were formed during two important steps which are emulsification step and dilution step. For emulsification step, isocyanate end-group of MDI reacts with water at the interface to form urea, which is unstable and dissociates into a chain with amine end-group $\left(-\mathrm{NH}_{2}\right)$ and carbon dioxide $\left(\mathrm{CO}_{2}\right)$. The formation of carbon dioxide by this shell formation reaction contributes significantly to the nanocapsules porosity. Subsequently, the chain of amine end-group reacts with an isocyanate group to form a urea linkage or polyurea. Isocyanate end-group of MDI also reacts with hydroxyl group of BDO to form a urethane as shown in Fig. 1.

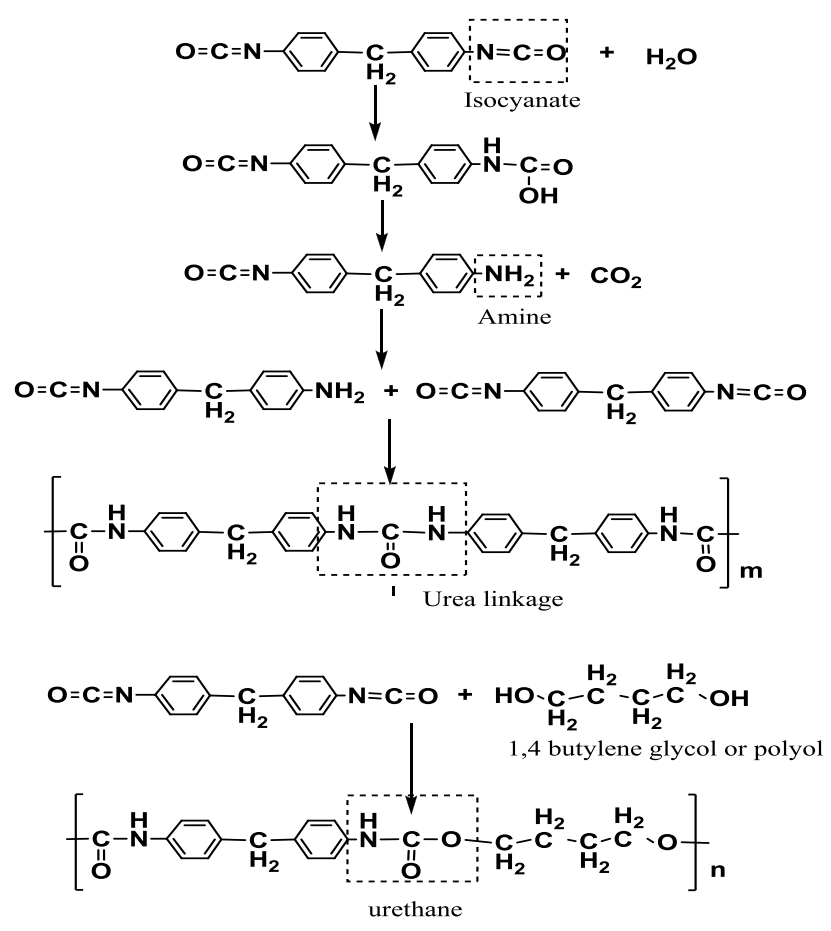

Fig. 1. Reaction schemes of polyurea and polyurethane shells.

For dilution step, the large quantity of distilled water was added during this step to allow diffusion of ethyl acetate from the internal phase to external phase, and then leads to the formation of nanocapsules [10]-[13].

Fig. 2 shows the FTIR spectra of polyurethane sample, Cassia alata leave extract and the produced nanocapsules. Spectrum of polyurethane sample showed an absorption band 
at $3484 \mathrm{~cm}^{-1}$ which corresponding to $\mathrm{N}-\mathrm{H}$ stretching. The band at 1667 and $1389 \mathrm{~cm}^{-1}$ are $\mathrm{C}=\mathrm{O}$ stretching and $\mathrm{C}-\mathrm{N}$ stretching. Spectrum of Cassia alata leave extract showed board absorption band at $3200-3500 \mathrm{~cm}^{-1}$ which assigned to $-\mathrm{OH}$ of remaining moisture in the extract. The bands at 1401 and $1205 \mathrm{~cm}^{-1}$ are found in the spectrum of Cassia alata leave extract. The C-O stretching absorption bands appear at 1258 and $925 \mathrm{~cm}^{-1}$. Furthermore, a broad absorption peak at 1072 $\mathrm{cm}^{-1}$ can be observed, which corresponds to the in plane bending mode of the amines. The produced nanocapsules FTIR spectrum showed the broad absorption peak at 3439 $\mathrm{cm}^{-1}$. The peaks at $2935 \mathrm{~cm}^{-1}$ can be assigned to the $\mathrm{C}-\mathrm{H}$ stretching modes and deformation of methyl groups. The strong peak at $1636 \mathrm{~cm}^{-1}$ corresponds to the carbonyl stretching vibration. An indication of the extract encapsulated in polyurethane nanocapsules might be the missing of $-\mathrm{OH}$ stretching board band in nanocapsules and the shift of N-H stretching band which probably due to intermolecular hydrogen bonding between Cassia alata leave extract and polyurethane shell.

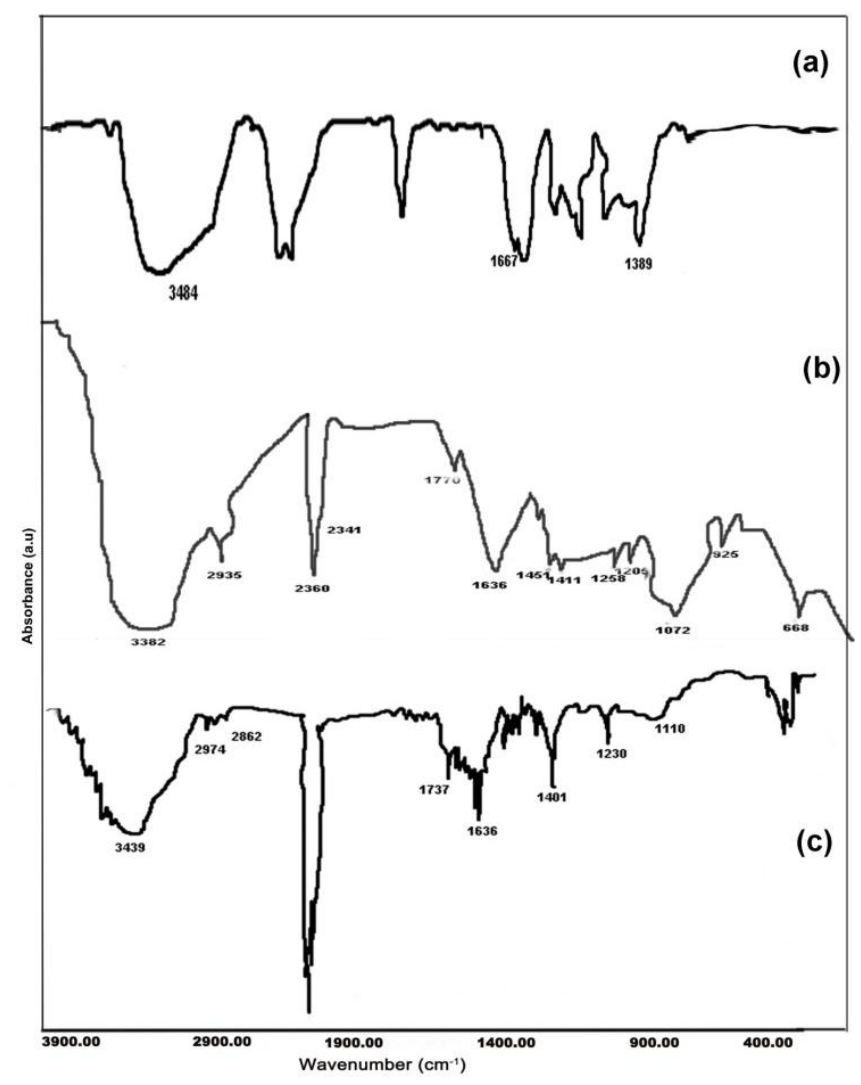

Fig. 2. FTIR spectra of polyurethane sample (a), Cassia alata leave extract (b) and nanocapsules containing Cassia alata leave extract (c).

\section{B. Encapsulation Yield of Nanocapsules Containing Cassia alata Leaves Extract}

The encapsulation yield ranges from $33.03 \%$ to $76.62 \%$ depending on the investigated parameters (Table I and Table II). The results revealed the dilution time has significant influence on the encapsulation yield but stirring speed does not have a significant effect on the encapsulation yield. Increasing of dilution time from 2 hours to 6 hours, decrease the encapsulation yield. In general, nanocapsules formation occurs in the following steps, i.e. polycondensation at droplet surface the formation of a primary shell around the droplet and a subsequent growth of the shell to obtain the final wall particle. The sufficient dilution time provides the optimum permeability properties of wall which lead to high encapsulation yield. Encapsulation yield, which obtained from dilution time of the 6 hour experiment, was less than other experiments. It might be due to $\mathrm{CO}_{2}$ that generated from the hydrolysis of isocyanate at a long dilution time may be higher than $\mathrm{CO}_{2}$ that generated from short dilution time, contribute to a less compact structure formation and increase the porosity of the capsules [10]-[13].

TABLE II: EXPERIMENTAL RESULTS

\begin{tabular}{cccccc}
\hline \hline & & & & Mean \\
Sample & $\begin{array}{c}\text { Speed } \\
\text { (rpm) }\end{array}$ & $\begin{array}{c}\text { Dilution } \\
\text { time (h) }\end{array}$ & $\begin{array}{c}\text { Encapsulation } \\
\text { yield }(\%)\end{array}$ & $\begin{array}{c}\text { Volume } \\
\text { of small } \\
\text { fraction } \\
\text { size } \\
\text { population } \\
\text { (nm) }\end{array}$ & $\begin{array}{c}\text { small size } \\
\text { population }\end{array}$ \\
& & & & $308 \pm 110$ & 35.40 \\
\hline 1 & 4050 & 2 & 69.93 & $318 \pm 140$ & 22.40 \\
2 & 6500 & 2 & 73.20 & $308 \pm 110$ & 35.43 \\
3 & 8100 & 2 & 79.05 & $327 \pm 110$ & 29.26 \\
4 & 4050 & 4 & 57.66 & $349 \pm 110$ & 28.88 \\
5 & 6500 & 4 & 60.21 & $338 \pm 170$ & 18.24 \\
6 & 8100 & 4 & 58.72 & $327 \pm 110$ & 30.01 \\
7 & 4050 & 6 & 42.86 & $327 \pm 110$ & 30.01 \\
8 & 6500 & 6 & 35.24 & & \\
9 & 8100 & 6 & 50.29 & & \\
\hline \hline
\end{tabular}

\section{Particle Size Distribution of Nanocapsules Containing} Cassia alata Leaves Extract

The mean size and size distribution of Cassia alata leave extract loaded polyurethane nanocapsules were determined by laser diffraction particle size analyzer. Fig. 3 illustrated size distribution of of nanocapsules loaded Cassia alata leave extract which prepared at dilution time of $2 \mathrm{~h}$ with different stirring rate, from 4050 to $8100 \mathrm{rpm}$. According to the results shown in Table II and the size distribution graph, there are two modes of size distribution which are small size and large size distribution. The smallest size is $308 \pm 110 \mathrm{~nm}$ which obtained from stirring speed of 4050 and $8100 \mathrm{rpm}$ at dilution time of $2 \mathrm{~h}$. The largest size is $349 \pm 110 \mathrm{~nm}$ which obtained from stirring speed of $6500 \mathrm{rpm}$ dilution time of $4 \mathrm{~h}$. The stirring speed and dilution time do not seem to have a significant effect on particle size distribution. Furthermore, size distribution of samples shows the bimodal distribution mode (and others not reported). This might be due to the reactions occurring during shell synthesis. During the shell formation, there are three competitive reactions which are isocyanate and water, isocyanate and emulsifier as well as isocyanate and BDO. The reaction between isocyanate and BDO is lower than isocyanate and emulsifier. The consumption of emulsifier during shell formation results in the drop instability, therefore they tend to merge to larger size [10]. Moreover, it can be related to the agglomeration of small size nanocapsules which resulted in larger size of nanocapsule.

\section{Morphology Investigation of Nanocapsules Containing} Cassia alata Leaves Extract

Morphologies of nanocapsules loaded Cassia alata leaves extract were investigated by scanning electron microscopy (SEM). 

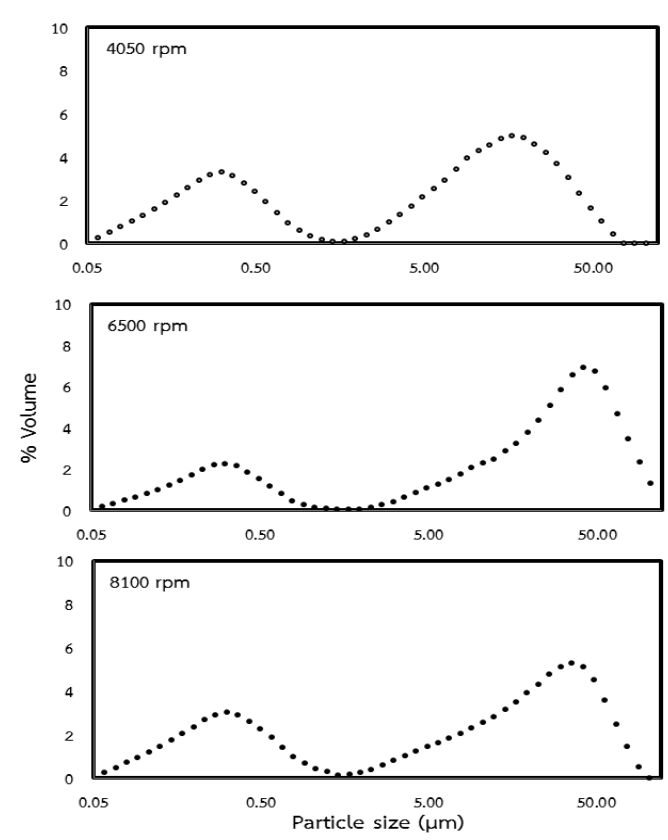

Fig. 3. Particle size distribution of nanocapsules loaded Cassia alata leave extract.
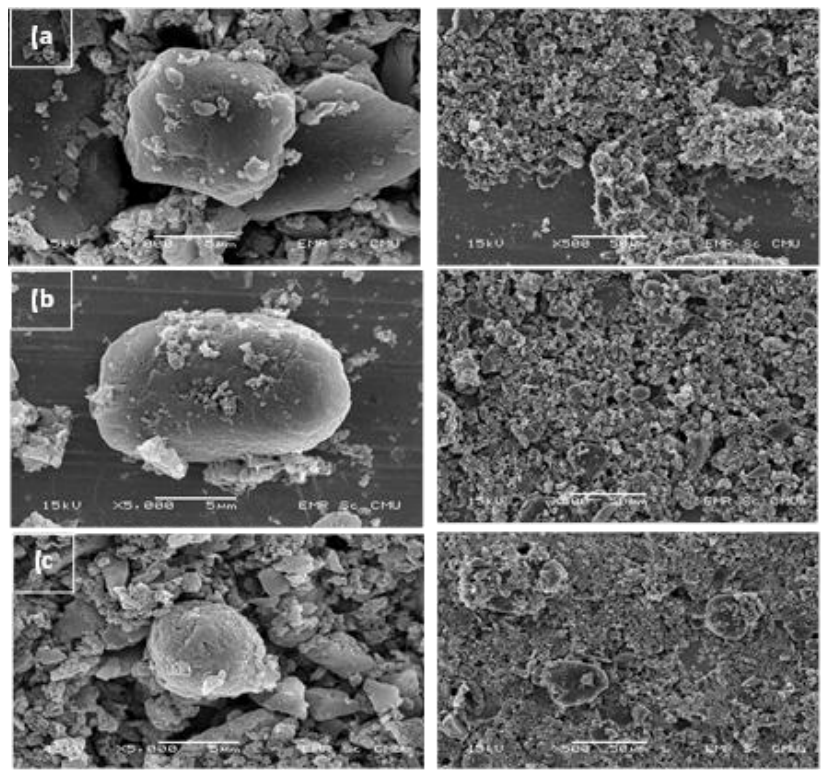

Fig. 4. SEM photographs of nanocapsules loaded Cassia alata leave extract which prepared at different stirring rates, $4050 \mathrm{rpm}$ (a) , $6500 \mathrm{rpm}$ (b) and $8100 \mathrm{rpm}(\mathrm{c})$.

Fig. 4 showed surface morphologies of nanocapsules loaded Cassia alata leaves extract which prepared at different stirring rate from 4050 to $8100 \mathrm{rpm}$ for dilution time of $2 \mathrm{~h}$. The SEM images showed rather spherical shape and smooth surface. However nanocapsules which prepared at $8100 \mathrm{rpm}$ presented rougher surface than the other.

\section{E. Antibacterial Activity}

Cassia alata leaves extract and cotton fabrics finished with resultant nanocapsules were tested antibacterial function against Staphylococcus aureus. Photograph of inhibition zone of Cassia alata leaves extract and cotton fabrics finished with nanocapsules containing Cassia alata leaves extract was shown in Fig. 5. The results indicated that Cassia alata leaves extract showed antibacterial activity against Staphylococcus aureus. However cotton fabric treated with nanocapsules showed less inhibition zone than Cassia alata leaves extract. This might be due to the amount of nanocapsuled that finished on cotton fabric is not enough to against Staphylococcus aureus when compared to the test of pure Cassia alata leaves extract.

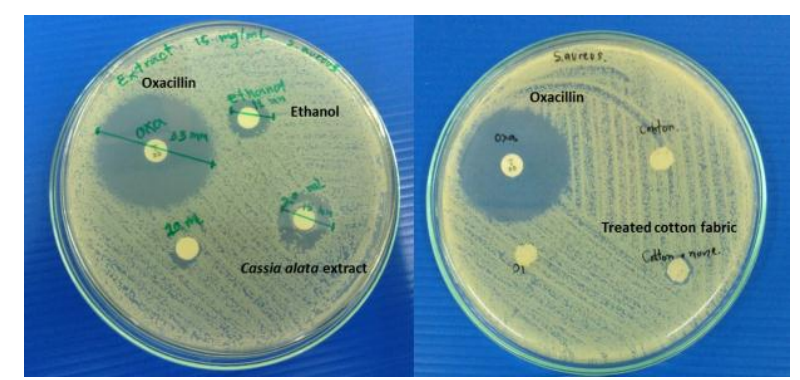

Fig. 5. Photographs showing inhibition zones of Cassia alata leave extract and cotton fabrics finished with nanocapsules containing Cassia alata leave extract.

\section{CONCLUSION}

In the present study, polyurethane nanocapsules containing Cassia alata leaves extract were successfully synthesized by emulsion-diffusion method. The chemical analysis by FTIR indicated Cassia alata leaves extract loaded nanocapsules. The encapsulation yield ranged from $33.03 \%$ to $76.62 \%$ depending on the experimental parameters. The particle size distribution of samples was determined using a laser dispersion technique. The results showed the bimodal size distribution in volume. The mean particle size of nanocapsules which obtained from the small size distribution area was in the range of 308-349 nanometers. SEM images showed rather spherical shape and smooth surface nanocapsules. Nanocapsules containing Cassia alata leaves extract were applied as a finishing agent for cotton fabrics to investigate antibacterial properties. The finished cotton fabrics revealed antibacterial activity against Staphylococcus aureus but less than crude Cassia alata leaves extract. The next works will be focused on other experimental parameters for encapsulation process and further study on releasing control and durability.

\section{ACKNOWLEDGMENT}

The authors wish to gratefully acknowledge research administration center and the graduate school of Chiang Mai University for the research grant. The authors would like to thank Dr. Kannipa Tasanapak (Naresuan University) for antimicrobial testing.

\section{REFERENCES}

[1] T. Ramachandran, K. Rajendrakumar, and R. Rajendran, "Antimicrobial textiles and overview," (IELI) Journal TX, vol. 84, pp 42-47, 2004

[2] N. Sowasod, T. Charinpanitkul, and W. Tanthapanichakoon "Nanoencapsulation of curcumin in biodegradable chitosan via multiple emulsion/solvent evaporation," in Proc. Thailand Material Science and Technology Conference 4th, 2006.

[3] M. Sumithra and N. Vasugi, "Micro and nano-encapsulation of denim fabrics with herbal extracts," Indian J. Fibre Text. Res., vol. 37, pp 321-325, December 2012.

[4] P. C. L. Hui, W. Y. Wang, C. W. Kan, C. E. Zhou, F. S. F. Ng, E. Wat, V. X. Zhang, C. L. Chan, C. B. S. Lau, and P. C. Leung, "Preparation 
and characterisation of chitosan microcapsules loaded with Cortex Moutan," Int. J. Biol. Macromol., vol. 55, pp. 32-38.

[5] D. Vijayalakshmi, R. Rathinamoorthy, and T. Ramachandran, "An experimental study on the multi-functional efficacy of nano $\mathrm{TiO}_{2}$ treated denim fabrics," JTATM, vol. 7, issue 4, pp. 1-12, 2012.

[6] C. Azubuike, "Evaluation of the antibacterial activity of herbal ointments formulated with methanolic extract of Cassia alata," AJBPS, vol. 2, pp. 15-19, 2012.

[7] J. H. Doughari and B. Okafor, "Antimicrobial activity of senna alata linn," East and Central African Journal of Pharmaceutical Sciences, vol. 10, pp. 17-21, 2007.

[8] S. Y. Timothy, F. W. Lamu, A. S. Rhoda, R. G. Adati, I. D. Maspalma, and M. Askira, "Acute toxicity, phytochemistry and antibacterial activity of aqueous and ethanolic leaf extracts of Cassia Alata Linn," IRJP, vol. 3, issue 6, pp. 73-76, 2012

[9] Z. U. Faruq, U. A. Rahman, M. Bello, M. Obianke, and F. A. Atiku, "Antibacterial activity of the active component of Cassia alata (Linn) leaves," Niger. J. Basic Appl. Sci., vol 18, issue 1, pp. 97-100, 2010.

[10] H. Souguir, F. Salaun, P. Douillet, I. Vroman, and S. Chatterjee, "Nanoencapsulation of curcumin in polyurethane and polyurea shells by an emulsion diffusion method," Chem. Eng. J., vol. 221, pp. 133-145, 2013.

[11] E. Jabbari and M. Khakpour, "Morphology of and release behavior from porous polyurethane microspheres," Biomaterials, vol. 21, pp. 2073-2079, 2000.

[12] R. Arshady, "Preparation of microspheres and microcapsules by interfacial polycondensation techniques," J. Microencapsul., vol. 6, pp. 13-28, 1989.

[13] Salaüna, G. Bedeka, E. Devauxa, D. Dupontb, and L. Gengembre, "Microencapsulation of a cooling agent by interfacial polymerization:
Influence of the parameters of encapsulation on poly(urethane-urea) microparticles characteristics," J. Membr. Sci., vol. 370, pp. 23-33, 2011.

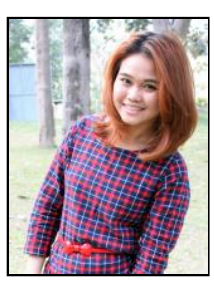

Donnapha Prateepthong was born in Nakhonsawan, Thailand on April 11, 1989. She received her bachelor's degree in chemistry from Naresuan University. At present, She is doing master's degree in industrial chemistry at the Department of Industrial Chemistry, Faculty of Science, Chiang Mai University, Her research activities are in the area of encapsulation and textile finishing.

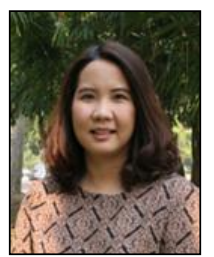

Sunsanee Komboonchoo is a lecturer at the Department of Industrial Chemistry, Faculty of Science, Chiang Mai University. Her research activities are in the area of natural dyeing and textile technology. 